\title{
A Vital Staining Practice That Discerns Ancestry within Groups of Settling Larvae of a Brooding Coral
}

\author{
Dor Shefy ${ }^{1,2,3, *}$, Nadav Shashar ${ }^{2}\left(\mathbb{D}\right.$ and Baruch Rinkevich ${ }^{1}$ \\ 1 Israel Oceanography and Limnological Research, National Institute of Oceanography, Tel-Shikmona, \\ P.O. Box 8030, Haifa 31080, Israel; buki@ocean.org.il \\ 2 Marine Biology and Biotechnology Program, Department of Life Sciences, Ben-Gurion University \\ of the Negev, Eilat Campus, Beer-Sheva 84105, Israel; nadavsh@bgu.ac.il \\ 3 The Interuniversity Institute for Marine Science, Eilat 88000, Israel \\ * Correspondence: shefy@post.bgu.ac.il
}

check for updates

Citation: Shefy, D.; Shashar, N.; Rinkevich, B. A Vital Staining Practice That Discerns Ancestry within Groups of Settling Larvae of a Brooding Coral. J. Mar. Sci. Eng. 2021, 9, 616. https://doi.org/10.3390/ jmse9060616

Academic Editor: Francesca Cima

Received: 28 April 2021

Accepted: 31 May 2021

Published: 3 June 2021

Publisher's Note: MDPI stays neutral with regard to jurisdictional claims in published maps and institutional affiliations.

Copyright: (c) 2021 by the authors. Licensee MDPI, Basel, Switzerland. This article is an open access article distributed under the terms and conditions of the Creative Commons Attribution (CC BY) license (https:// creativecommons.org/licenses/by/ $4.0 /)$.

\begin{abstract}
Xenogeneic and allogeneic encounters following aggregated and clustered settlements of coral larvae (planulae) may carry important ecological consequences in shaping coral reefs ${ }^{\prime}$ communities. However, larval settlement behaviors and settlement location choices in the presence of conspecifics or heterospecifics have not been examined in detail, due to a lack of experimental tools. One potential approach is the employment of vital staining of planulae with dyes that do not impair larval metamorphosis processes, are stable for prolonged periods, and do not diffuse to un-labeled counterpart planulae. For these purposes, we examined the use of neutral red (NR) dye, as an identification marker, on the planulae of Stylophora pistillata, a Red Sea branching coral species. To examine possible NR impacts on larval settlement in the presence of conspecific planulae, we followed the settlement ratios of kin, non-kin, and mixed assemblages, as a proxy for metamorphosis success. We found no differences in settlement rates of stained vs. unstained larvae, lack of stain diffusion to other larvae and that NR stain is maintained for more than a week under a still water regimen. Thus, staining with NR may serve as a useful experimental tool, opening new opportunities in studying larval settlement patterns in sessile marine organisms.
\end{abstract}

Keywords: chimerism; settlement; planulae; neutral red; aggregation; Stylophora pistillata; larval behavior

\section{Introduction}

A coral's life-cycle includes a pelagic larval stage (planula), larval settlement and metamorphosis to a primary polyp (a colony founder), astogenic growth via budding of polyps and/or branches, and sexual reproduction. When selecting a spatial location, the attachment to the substrate, settlement, and metamorphosis are active responses of the planulae to cues from substrates and the surrounding environments [1-3]. The choice of any specific site, in the context of habitat, substrate, water conditions, turf organisms, and other sessile neighbors, shapes the success of recruitment and the future of the coral reefs [1,4-6]. Although environmental factors such as substrate types, textures, chemical compositions, and physical cues for settlement have been extensively studied, the effect of various traits, such as the possible impacts of conspecifics or heterospecifics on settlement and choice of site, was less investigated.

Allogeneic (with conspecifics) or xenogeneic (with members of other species) encounters following the aggregated settlement of coral larvae have been reported for more than a century in various coral reefs worldwide [7-14]. While xenogeneic encounters of corals always result in interspecific conflicts between the partners, including the development of necrotic zones between interacting young colonies (rejection phenomena; $[6,15,16]$ ), allogeneic encounters may not only result in rejection but also tissue fusions between conspecifics, leading to the formation of chimeric colonies [6,15-17]. These outcomes have sig- 
nificant impacts on corals' survivorship, physiology, fitness, and morphology [6,16,18-20]. The wide distribution of coral chimerism in nature is another indication that aggregated settlement of coral larvae is common, beyond what has been thought [21-26] (Figure 1a). However, the lack of appropriate tools limited research activities on aggregated settlements and the impacts of planulae origin.

To follow larval origin within a group of settled planulae, one should obtain the competence to label or tag specific larvae within the assemblage. First, the labeling/tagging method should not interrupt the planktonic phase, the settlement processes, and the metamorphosis into the polyp stage. Second, the identifier mark should be easily detected under regular laboratory conditions without the involvement of sophisticated equipment. A third requirement is the need for prolonged labeling durations targeting successive observations.

Here, we developed and tested a method to label coral larvae using the vital stain neutral red. Neutral red (3-Amino-7-dimethylamino-2-methylphenazine hydrochloride) is a relatively non-toxic dye used for staining of histological sections [27], employed as an intracellular $\mathrm{pH}$ indicator [28], as an ecological/biological marker for animal movement and embryogenesis [29,30], and as a textile dye [31]. The use of neutral red began in the 1940 s as a means to study the dispersion and movement of larvae of oysters, barnacles, and copepods [32]. The past restricted use of neutral red dye as a color marker in cnidarians was for studying embryo's polarity in the hydrozoan Clytia gregaria (previously known as Phialidium gregarium) [30]), where again, the development of the embryo to a planula was not affected by the dye.

We labeled the planulae of the branching coral Stylophora pistillata, one of the most abundant coral species in the Gulf of Eilat, Red Sea (Figure 1b). S. pistillata is a hermaphrodite species characterized by a long reproductive season and with colonies that release to the water column ready-to-settle planulae on a daily basis [33-35]. Most of the planulae of S. pistillata settle within the first $48 \mathrm{~h}$ upon release, and no substrate fastidiousness has been recorded [36-38]. We tested settlement success and effective metamorphosis by comparing settlement ratios among neutral red-stained and unstained larvae.

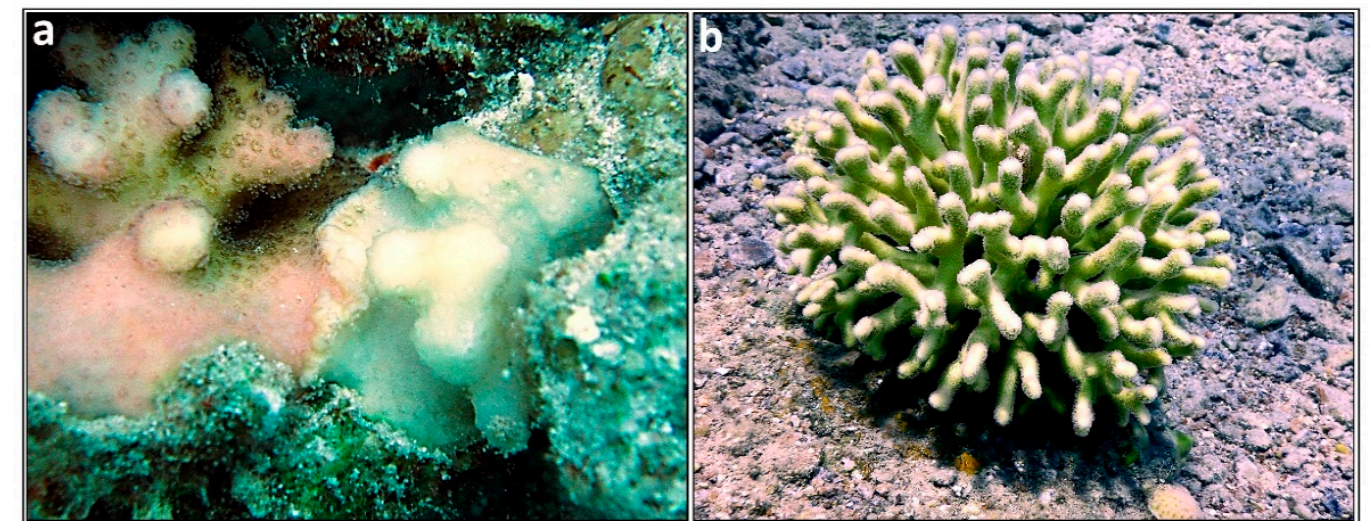

Figure 1. (a) The allogeneic encounter of two juvenile colonies of S. pistillata. These two individuals did not fuse, and they stay in constant conflict interactions [39]. (b) An adult colony of S. pistillata in Eilat's shallow reef. Both photos were taken in the northern Gulf of Eilat using a Canon G7 camera.

\section{Materials and Methods}

\subsection{Experimental Design}

Planulae of Stylophora pistillata were collected between February to July 2020 from 15 gravid colonies residing at 3-12 $\mathrm{m}$ in front of the Inter-University Institute of Marine Science in Eilat, Israel. Planulae were collected using planulae traps as described in Shefy et al. [35] and transferred to Petri dishes $(9.5 \mathrm{~cm}$ diameter) in accordance with the experimental design. 
Sets of three labeling treatments were established for planulae collected from the same/different maternal colonies, establishing the scenario where each Petri dish in a treatment contains 20 planulae of: (1) Neutral red un-stained controls (Figure 2a); (2) Neutral red labeled planulae (Figure 2b); (3) Neutral red mix treatment: 10 stained planulae originated from one colony and 10 un-stained planulae from a different colony. Each Petri dish was covered with a polyester film ("Maylor paper"; Jolybar, Israel), and preconditioned for one month for the development of microbial films that support coral larvae settlement $[12,40]$. The dishes were mostly $(75 \%)$ submerged in the table's water volume, supplied with running seawater to keep ambient temperature, and covered with a lid to minimize evaporation. Water in the Petri dishes was replaced each day with fresh seawater to prevent mucus accumulation and to keep seawater salinity constant, as in natural waters ( $40.6 \mathrm{ppt})$. The dishes were monitored for a week. Settlement rate, as well as the existence of the stain, were recorded daily.
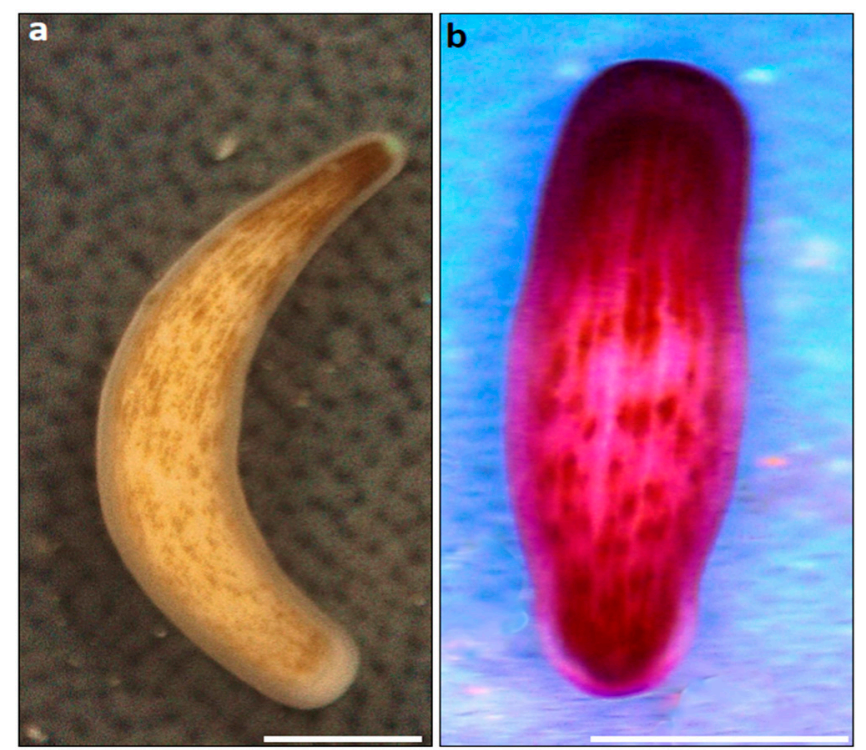

Figure 2. (a) An unstained planula. (b) A stained planula. Both photos were photographed using a $3.5 \times-90 \times$ trinocular stereo microscope (AmScope) equipped with a $10 \mathrm{MP}$ USB microscope digital camera. Scale bar is $500 \mu \mathrm{m}$ in both photos.

\subsection{Staining Procedures}

We first tested methylene blue, cyber green, and neutral red as these dyes were used to stain marine invertebrate larvae [32]. Preliminary results revealed that methylene blue and cyber green did not stain the coral planulae.

Staining was thus executed using the neutral red dye (Aldrich Chemical, Milwaukee, WI, USA). A stock solution of $1 \%$ was prepared by mixing $100 \mathrm{~mL}$ of filtered seawater with $1 \mathrm{~g}$ of neutral red powder. For planulae staining, planulae were immersed for $1-5 \mathrm{~min}$ in a Petri dish filled with the stock solution. Before the planulae were transferred to the experimental dishes, they were washed by moving them to a different dish filled with fresh seawater for $5 \mathrm{~min}$, followed by a $10 \mathrm{~min}$ immersion in another dish filled with fresh seawater. Planulae were transferred between dishes using a Pasteur pipette to reduce any mechanical damage that may be developed using other washing procedures (such as washing through a mesh; D.S personal observation).

\subsection{Statistical Analysis}

The statistical analyses of the settlement ratios of S. pistillata larvae were performed using R software [41]. After checking for the assumptions (Shapiro-Wilk test $p>0.05$; Levene's test $p>0.05$ ), we used a one-way ANOVA to compare settlement among treatments. Since in the 'mix' treatment, stained and un-stained planulae were in the same dish, 
comparison between their mean settlement rates was conducted by a paired $t$-test. For comparison of the overall settlement of the stained larvae in the mix and stained treatment vs. un-stained larvae in the mix and un-stained treatment, a two-sample $t$-test was used.

\section{Results}

We first tested immersion duration in neutral red solution for various time-points of 1,2,3,4, and $5 \mathrm{~min}$. Planulae immersed for 1-4 min resulted in different red shades between planulae or stained with a pale reddish color that dissipated within a few days in the dish. Only 5 min immersion time and prolonged durations resulted in a deep coloration of all stained larvae; thus, the time slot of 5 min immersion duration was inferred as optimal.

Most S. pistillata planulae settled within the first $48 \mathrm{~h}$ after their release, and observations were followed on larvae and primary polyps in the sealed dished for up to 1 week. The red stain was noticeably retained for the whole observational period, clearly distinguishing the stained from non-stained larvae. Settled stained larvae and metamorphosed spats continued to exhibit the neutral red stain (Figure $3 a, b$ ). The stained planktonic larvae were vital, actively changing locations in the dishes, as the controls, until metamorphosed (Figure 2b). Following the one-week observational period, the Petri dishes with the settled primary polyps were transferred to a large container (water-table) with running seawater. At this stage, all primary polyps lost their red color after no longer than three additional days.
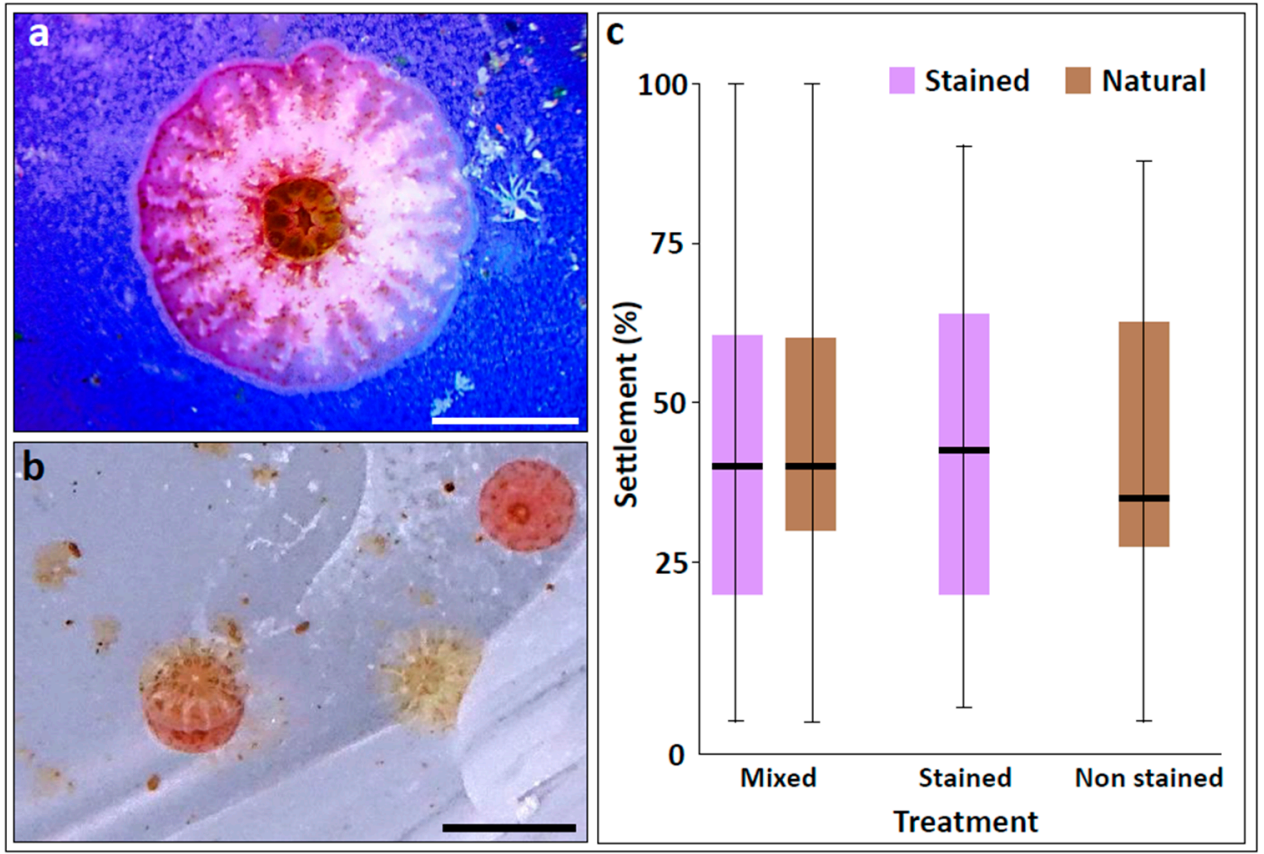

Figure 3. (a,b) Two days post-settlement. (a) A primary polyp developed from a stained planula. Scale bar is $500 \mu \mathrm{m}$. (b) A clustered settlement of two stained and two un-stained planulae that settled and metamorphosed. One stained and one unstained aggregate. Scale bar is $1000 \mu \mathrm{m}$. (c) Box plot for settlement percentages. Lower and upper hinges correspond to the 25 th and 75 th percentiles. The upper/lower whisker extends from the hinge to the largest/smallest value of $1.5 \times \mathrm{IQR}$ (interquartile range) from the hinge. The horizontal line corresponds to the median value. Brown boxes refer to unstained planulae and purple boxes to the stained planulae in each treatment.

In total, 42 dishes were assigned to the mixed treatment, 15 to the non-stained treatment, and 19 to the stained treatment. Under these conditions, $43.9 \pm 3.6 \%$ (mean $\pm \mathrm{SE}$ ) of all planulae (regardless of the treatment) successfully settled and metamorphosed, $42.5 \pm 6.3 \%, 40.7 \pm 5.7 \%$ and $44.5 \pm 3.5 \%$ of the non-stained larvae dishes, the stained larvae dishes and the mix dishes, respectively (one way ANOVA: $\mathrm{F}_{2,73}=0.73, p=0.49$; 
Figure $3 c$ ). In the mix treatment, $46.0 \pm 4.7 \%$ and $45.1 \pm 4.2 \%$ of the stained and the nonstained planulae were settled, again, with no significant difference (paired $t$-test: $t_{40}=0.06$, $p>0.8$; Figure 3c). Focusing on the stained larvae, the overall mean settled stained planulae in the mix and stained dishes was $44.4 \pm 3.7 \%$, as compared to $44.4 \pm 3.5 \%$ for the non-stained planulae (mix and non-stained; $t$-test: $\mathrm{t}_{115}=-0.18, p>0.8$; Figure $3 \mathrm{c}$ )

\section{Discussion}

This study has tested and established the use of neutral red dye as a useful way for labeling coral planulae, amenable for follow-up studies for at least 3 days under constant flow and more than a week under a still water regimen. Using S. pistillata as a model case, we demonstrated that staining planulae of a brooding species with neutral red is a safe and reliable labeling procedure that does not harm larval behavior, settlement, and metamorphosis and that the stain is not leaking to unlabelled larvae within the same dish. Stained larvae/primary polyps were clearly distinguished by color from unstained counterparts, using the naked eye and without employing any sophisticated equipment. Using the settlement percentages as a proxy for the potentially harmful effects of the labeling, we found no significant differences in settlement percentages between stained and non-stained planulae, including the mixed dishes where planulae originated from different maternal colonies. An additional advantage to the new labeling practice is its low cost, without necessitating the use of genetic markers or observations under special illumination, such as fluorescent light. Though not tested here, the use of neutral red to label planulae and release them in situ may reveal an additional research pathway in coral biology studies. The same implies to the use of neutral red with planulae from broadcasting coral species, though the literature attests that neutral red stain does not damage the embryogenesis of other cnidarian species [30]. Aggregated and clustered settlements of larvae are continuously reported for various coral species [8-14]. However, despite the ecological importance of larval settlement behavior, the pattern of settlement as shaped by the inter- and intraspecific interactions of larvae in the aggregated settlers remains poorly understood. The literature depicts that newly settled juveniles have higher fusion probabilities between kin [12,42-46]. However, lacking feasible labeling methodologies, previous studies commonly approached the lack of partner identifications by artificially gluing/actively attaching coral spat/colonies next to each other, enforcing the close settlement of planulae without the opportunity to test the natural choices of planulae in a pair.

There has been a resurgence in scientific interest in the importance of the larval settlement phase in the coral population $[1,47,48]$, including studies that considered planulae seeding as a reef restoration strategy approach $[13,14,49-54]$. Further, corals' xenogeneic and allogeneic interactions in the reef may affect various life-history traits [15,55-57], shaping community structures and population dynamics [55,58]. Using the neutral red labeling method will provide another experimental tool for studying the detailed settlement patterns of kin and non-kin coral larvae for improved yields of coral colonies amenable for the coral transplantation or larval seeding in the reef.

Author Contributions: Conceptualization, D.S., B.R.; methodology, D.S.; software, D.S.; validation, D.S., B.R.; formal analysis, D.S.; investigation, D.S.; resources, B.R.; data curation, D.S.; writingoriginal draft preparation, D.S. and B.R.; writing-review and editing, D.S., B.R. and N.S.; visualization, D.S.; supervision, B.R., N.S.; project administration, B.R.; funding acquisition, B.R. All authors have read and agreed to the published version of the manuscript.

Funding: This research was funded by the AID-MERC (M33-001), the Israeli-French High Council for Scientific and Technological Research Program (Maïmonide-Israel), the North American Friends of IOLR (NAF/IOLR), and the Barrett Foundation.

Institutional Review Board Statement: Not applicable.

Informed Consent Statement: Not applicable. 
Data Availability Statement: The data presented in this study are available in request from corresponding author.

Acknowledgments: We wish to thank O. Ben-Zvi for the creative ideas, to G. Paz for assisting with visualization and $Z$. Lapidot for assisting with staining.

Conflicts of Interest: The authors declare no conflict of interest.

\section{References}

1. Ritson-Williams, R.; Arnold, S.N.; Fogarty, N.D.; Steneck, R.S.; Vermeij, M.J.A.; Paul, V.J. New perspectives on ecological mechanisms affecting coral recruitment on reefs. Smithson. Contrib. Mar. Sci. 2009, 437-457. [CrossRef]

2. Tebben, J.; Motti, C.A.; Siboni, N.; Tapiolas, D.M.; Negri, A.P.; Schupp, P.J.; Kitamura, M.; Hatta, M.; Steinberg, P.D.; Harder, T. Chemical mediation of coral larval settlement by crustose coralline algae. Sci. Rep. 2015, 5, 10803. [CrossRef] [PubMed]

3. Birrell, C.L.; McCook, L.J.; Willis, B.L. Effects of algal turfs and sediment on coral settlement. Mar. Pollut. Bull. 2005, 51, 408-414. [CrossRef] [PubMed]

4. Richmond, R.H. Reproduction and recruitment in corals: Critical links in the persistence of reefs. In Life Death Coral Reefs; Chapman Hall: New York, NY, USA, 1997; pp. 175-197.

5. Arnold, S.N.; Steneck, R.S. Settling into an Increasingly Hostile World: The Rapidly Closing "Recruitment Window" for Corals. PLoS ONE 2011, 6, e28681. [CrossRef]

6. Rinkevich, B. Neglected biological features in Cnidarians self-nonself recognition. In Self-NonSelf Recognition; López-Larrea, C., Ed.; Springer: New York, NY, USA, 2012; pp. 46-59.

7. Duerden, J.E. Aggregated Colonies in Madreporarian Corals. Am. Nat. 1902, 36, 461-471. [CrossRef]

8. Goreau, N.I.; Goreau, T.J.; Hayes, R.L. Settling, survivorship and spatial aggregation in planulae and juveniles of the coral Porites porites (Pallas). Bull. Mar. Sci. 1981, 31, 424-435.

9. Neves, E.G.; Silveira, F.L. Release of planula larvae, settlement and development of Siderastrea stellata Verrill, 1868 (Anthozoa, Scleractinia). CEUR Workshop Proc. 2000, 1621, 36-43. [CrossRef]

10. Barki, Y.; Gateño, D.; Graur, D.; Rinkevich, B. Soft-coral natural chimerism: A window in ontogeny allows the creation of entities comprised of incongruous parts. Mar. Ecol. Prog. Ser. 2002, 231, 91-99. [CrossRef]

11. Puill-Stephan, E.; van Oppen, M.J.H.; Pichavant-Rafini, K.; Willis, B.L. High potential for formation and persistence of chimeras following aggregated larval settlement in the broadcast spawning coral, Acropora millepora. Proc. R. Soc. Lond. Ser. B Biol. Sci. 2012, 279, 699-708. [CrossRef]

12. Amar, K.O.; Chadwick, N.E.; Rinkevich, B. Coral kin aggregations exhibit mixed allogeneic reactions and enhanced fitness during early ontogeny. BMC Evol. Biol. 2008, 8, 126. [CrossRef]

13. Doropoulos, C.; Evensen, N.R.; Gómez-Lemos, L.A.; Babcock, R.C. Density-dependent coral recruitment displays divergent responses during distinct early life-history stages. R. Soc. Open Sci. 2017, 4, 170082. [CrossRef]

14. Cameron, K.A.; Harrison, P.L. Density of coral larvae can influence settlement, post-settlement colony abundance and coral cover in larval restoration. Sci. Rep. 2020, 10, 5488. [CrossRef]

15. Rinkevich, B.; Shashar, N.; Liberman, T. Nontransitive xenogeneic interactions between four common Red Sea sessile invertebrates. Proc. Seventh Int. Coral Reef Symp. 1993, 2, 833-839.

16. Rinkevich, B. Allorecognition and xenorecognition in reef corals: A decade of interactions. Hydrobiologia 2004, 530, 443-450. [CrossRef]

17. Rinkevich, B.; Weissman, I.L. Chimeras in colonial invertebrates: A synergistic symbiosis or somatic-cell and germ-cell parasitism? Symbiosis 1987, 4, 117-134.

18. Guerrini, G.; Shefy, D.; Shashar, N.; Shafir, S.; Rinkevich, B. Morphometric and allometric rules of polyp's landscape in regular and chimeric coral colonies of the branching species Stylophora pistillata. Dev. Dyn. 2020, 1-17. [CrossRef]

19. Shefy, D.; Shashar, N.; Rinkevich, B. Exploring traits of engineered coral entities to be employed in reef restoration. J. Mar. Sci. Eng. 2020, 8, 1038. [CrossRef]

20. Rinkevich, B. Coral chimerism as an evolutionary rescue mechanism to mitigate global climate change impacts. Glob. Chang. Biol. 2019, 25, 1198-1206. [CrossRef] [PubMed]

21. Noble, J.P.A.; Lee, D. First report of allogeneic fusion and allorecognition in tabulate corals. J. Paleontol. Soc. 1991, 65, 69-74. [CrossRef]

22. Puill-Stephan, E.; Willis, B.L.; van Herwerden, L.; van Oppen, M.J.H. Chimerism in wild adult populations of the broadcast spawning coral Acropora millepora on the Great Barrier Reef. PLoS ONE 2009, 4. [CrossRef] [PubMed]

23. Maier, E.; Buckenmaier, A.; Tollrian, R.; Nürnberger, B. Intracolonial genetic variation in the scleractinian coral Seriatopora hystrix. Coral Reefs 2012, 31, 505-517. [CrossRef]

24. Schweinsberg, M.; Weiss, L.C.; Striewski, S.; Tollrian, R.; Lampert, K.P. More than one genotype: How common is intracolonial genetic variability in scleractinian corals? Mol. Ecol. 2015, 24, 2673-2685. [CrossRef] [PubMed]

25. Rinkevich, B.; Shaish, L.; Douek, J.; Ben-Shlomo, R. Venturing in coral larval chimerism: A compact functional domain with fostered genotypic diversity. Sci. Rep. 2016, 6, 19493. [CrossRef] 
26. Giordano, B.; Bramanti, L. First report of chimerism in Mediterranean red coral (Corallium rubrum ). Mediterr. Mar. Sci. 2021, 22, 157-160. [CrossRef]

27. Guérard, M.; Zeller, A.; Singer, T.; Gocke, E. In Vitro genotoxicity of neutral red after photo-activation and metabolic activation in the Ames test, the micronucleus test and the comet assay. Mutat. Res. Genet. Toxicol. Environ. Mutagen. 2012, 746, 15-20. [CrossRef]

28. LaManna, J.C.; Mccracken, K.A. The use of Neutral Red as an intracellular pH Indicator in rat brain cortex in vivo. Analyt 1984, 142, 117-125. [CrossRef]

29. New, J.G. Dyes for studying the movements of small mammals. Am. Soc. Mammal. 1958, 39, 416-429. [CrossRef]

30. Freeman, G. The role of polarity in the development of the hydrozoan planula larva. Roux's Arch. Dev. Biol. 1981, 190, 168-184. [CrossRef]

31. Zhou, Q. Chemical pollution and transport of organic dyes in water-soil-crop systems of the chinese coast. Bull. Environ. Contam. Toxicol. 2001, 66, 784-793. [CrossRef] [PubMed]

32. Levin, L.A. A review of methods for labeling and tracking marine invertebrate larvae. Ophelia 1990, 32, 115-144. [CrossRef]

33. Rinkevich, B.; Loya, Y. The reproduction of the Red Sea coral Stylophora pistillata. I. Gonads and planulae. Mar. Ecol. Prog. Ser. 1979, 1, 145-152. [CrossRef]

34. Rinkevich, B.; Loya, Y. The reproduction of the Red Sea coral Stylophora pistillata. II. Synchronization in breeding and seasonality of planulae shedding. Mar. Ecol. Prog. Ser. 1979, 1, 133-144. [CrossRef]

35. Shefy, D.; Shashar, N.; Rinkevich, B. The reproduction of the Red Sea coral stylophora pistillata from Eilat: 4-decade perspective. Mar. Biol. 2018, 165, 1-10. [CrossRef]

36. Putnam, H.M.; Edmunds, P.J.; Fan, T.-Y. Effect of temperature on the settlement choice and photophysiology of larvae from the reef coral Stylophora pistillata. Biol. Bull. 2008, 215, 135-142. [CrossRef]

37. Baird, A.H.; Morse, A.N.C. Induction of metamorphosis in larvae of the brooding corals Acropora palifera and Stylophora pistillata. Mar. Freshw. Res. 2004, 55, 469-472. [CrossRef]

38. Tamir, R.; Eyal, G.; Cohen, I.; Loya, Y. Effects of light pollution on the early life stages of the most abundant northern Red Sea coral. Microorganisms 2020, 8, 193. [CrossRef]

39. Chadwick-Furman, N.; Rinkevich, B. A complex allorecognition system in a reef-building coral: Delayed responses, reversals and nontransitive hierarchies. Coral Reefs 1994, 13, 57-63. [CrossRef]

40. Baird, A.H. The Ecology of Coral Larvae: Settlement Patterns, Habitat Selection and the Length of the Larval Phase. Ph.D. Thesis, James Cook University of North Queensland, Queensland, Australia, 2001.

41. R Core Team R: A Language and Environment for Statistical Computing. 2014. Available online: https://www.r-project.org/ (accessed on 29 May 2021).

42. Hidaka, M.; Yurugi, K.; Sunagawa, S.; Kinzie, R.A. Contact reactions between young colonies of the coral Pocillopora damicornis. Coral Reefs 1997, 16, 13-20. [CrossRef]

43. Nozawa, Y.; Loya, Y. Genetic relationship and maturity state of the allorecognition system affect contact reactions in juvenile Seriatopora corals. Mar. Ecol. Prog. Ser. 2005, 286, 115-123. [CrossRef]

44. Amar, K.O.; Rinkevich, B. Mounting of erratic histoincompatible responses in hermatypic corals: A multi-year interval comparison. J. Exp. Biol. 2010, 213, 535-540. [CrossRef] [PubMed]

45. Wijayanti, D.P.; Hidaka, M. Is genetic involve in the outcomes of contact reactions between parent and offspring and between siblings of the coral Pocillopora damicornis? ILMU Kelaut. Indones. J. Mar. Sci. 2018, 23, 69. [CrossRef]

46. Frank, U.; Oren, U.; Loya, Y.; Rinkevich, B. Alloimmune maturation in the coral Stylophora pistillata is achieved through three distinctive stages, 4 months post-metamorphosis. Proc. R. Soc. Lond. Ser. B Biol. Sci. 1997, 264, 99-104. [CrossRef]

47. Doropoulos, C.; Ward, S.; Roff, G.; González-Rivero, M.; Mumby, P.J. Linking demographic processes of juvenile corals to benthic recovery trajectories in two common reef habitats. PLoS ONE 2015, 10, e128535. [CrossRef] [PubMed]

48. Vermeij, M.J.A.; Sandin, S.A. Density-dependent settlement and mortality structure the earliest life phases of a coral population. Ecology 2008, 89, 1994-2004. [CrossRef] [PubMed]

49. Rinkevich, B. Ecological engineering approaches in coral reef restoration. ICES J. Mar. Sci. 2020, 2100. [CrossRef]

50. Rinkevich, B. The active reef restoration toolbox is a vehicle for coral resilience and adaptation in a changing world. J. Mar. Sci. Eng. 2019, 7, 201. [CrossRef]

51. Linden, B.; Rinkevich, B. Elaborating an eco-engineering approach for stock enhanced sexually derived coral colonies. J. Exp. Mar. Biol. Ecol. 2017, 486, 314-321. [CrossRef]

52. Cruz, D.W.D.; Harrison, P.L. Enhanced larval supply and recruitment can replenish reef corals on degraded reefs. Sci. Rep. 2017, 7, 13985. [CrossRef]

53. Linden, B.; Vermeij, M.J.A.; Rinkevich, B. The coral settlement box: A simple device to produce coral stock from brooded coral larvae entirely in situ. Ecol. Eng. 2019, 132, 115-119. [CrossRef]

54. Amar, K.O.; Rinkevich, B. A floating mid-water coral nursery as larval dispersion hub: Testing an idea. Mar. Biol. 2007, 151, 713-718. [CrossRef]

55. Tanner, J.E. Interspecific competition reduces fitness in scleractinian corals. J. Exp. Mar. Biol. Ecol. 1997, 214, 19-34. [CrossRef]

56. Rinkevich, B.; Loya, Y. Intraspecific competitive networks in the Red Sea coral Stylophora pistillata. Coral Reefs 1983, 1, 161-172. [CrossRef] 
57. Frank, U.; Brickner, I.; Rinkevich, B.; Loya, Y.; Bak, R.P.M.; Achituv, Y.; Ilan, M. Allogeneic and xenogeneic interactions in reef-building corals may induce tissue growth without calcification. Mar. Ecol. Prog. Ser. 1995, 124, 181-188. [CrossRef]

58. Buss, L.W.; Jackson, J.B.C. Competitive networks: Nontransitive competitive relationships in cryptic coral reef environments. Am. Nat. 1979, 113, 223-234. [CrossRef] 